\title{
Radiation-induced lung injury: current evidence
}

\author{
Marisol Arroyo-Hernández', Federico Maldonado' , Francisco Lozano-Ruiz', Wendy Muñoz-Montaño', \\ Mónica Nuñez-Baez ${ }^{2}$ and Oscar Arrieta ${ }^{1 *}$ (D)
}

\begin{abstract}
Chemo-radiotherapy and systemic therapies have proven satisfactory outcomes as standard treatments for various thoracic malignancies; however, adverse pulmonary effects, like pneumonitis, can be life-threatening. Pneumonitis is caused by direct cytotoxic effect, oxidative stress, and immune-mediated injury. Radiotherapy Induced Lung Injury (RILI) encompasses two phases: an early phase known as Radiation Pneumonitis (RP), characterized by acute lung tissue inflammation as a result of exposure to radiation; and a late phase called Radiation Fibrosis (RF), a clinical syndrome that results from chronic pulmonary tissue damage. Currently, diagnoses are made by exclusion using clinical assessment and radiological findings. Pulmonary function tests have constituted a significant step in evaluating lung function status during radiotherapy and useful predictive tools to avoid complications or limit toxicity. Systemic corticosteroids are widely used to treat pneumonitis complications, but its use must be standardized, and consider in the prophylaxis setting given the fatal outcome of this adverse event. This review aims to discuss the clinicopathological features of pneumonitis and provide practical clinical recommendations for prevention, diagnosis, and management.
\end{abstract}

Keywords: Pneumonitis, Radiation pneumonitis, Radiation-induced lung injury, Lung cancer, Radiotherapy, Antineoplastic agents, Adverse effects

\section{Background}

For many years, radiotherapy (RT) has played an essential role in cancer treatments applied with curative intent or as an adjuvant treatment with chemotherapy or surgery [1]. It has also been used as a palliative remedy to alleviate symptoms in malignant and non-malignant disorders [2]. However, radiation-induced lung injury (RILI) is a severe complication of thoracic RT and embraces radiation pneumonitis $(\mathrm{RP})$ and radiation fibrosis (RF) [3]. With the advent of new forms of radiotherapy techniques, such as Stereotactic Body Radiation Therapy (SBRT) and Intensity-modulated radiotherapy (IMRT), delivery of beam arrays to the tumor and surrounding

\footnotetext{
*Correspondence: oscar.arrieta.r@gmail.com; ogarrieta@gmail.com ${ }^{1}$ Head of Thoracic Oncology Unit, Unidad Funcional de Oncología Torácica, Instituto Nacional de Cancerología (INCan), Av. San Fernando \#22, Sección XVI, Tlalpan, 14080 México City, CDMX, México

Full list of author information is available at the end of the article
}

tissues is more precise, reducing the incidence of lung toxicity. Risk factors related to the patient, treatment, and tumor can all influence the severity and extent of lung injuries. The challenge for diagnoses relies on the different clinical-radiological presentations and exclusion of alternative diagnoses, which explain the broad range of incidence rates (5\%-58\%) [4-7].

\section{Main text \\ Predisposing factors \\ Treatment-related factors}

1. Radiation therapy: RILI encompasses any lung damage due to lung exposure to ionizing radiation. This damage typically classified in early and late radiation toxicity could oscillate between asymptomatic and severe manifestations. Three common grading systems have used to stratify the severity of symptoms 
(see Table 1) [8]. In almost $40 \%$ of cases, conventional RT irradiates a considerable extension of healthy tissue surrounding the tumor. Therefore, new technologies of treatment delivery explored intensitymodulated RT (IMRT), volumetric arc radiotherapy (VMAT), and stereotactic body radiation therapy (SBRT) to highly individualized radiation treatment for primary tumors to minimize lung injury. In general, these techniques are well-tolerated, although major lung toxicity reported in up to $20 \%$ of cases [9, 10].

2. Lung dose: The total lung radiation dose is the main factor that predisposes to RP. The radiation doses delivered to the percentage of healthy lung tissue, receiving at least $20 \mathrm{~Gy}\left(\mathrm{~V}_{20}\right)$, link to the development of lung toxicity $[11,12]$. Additionally, low-dose parameters in the ipsilateral lung such as $V_{5}, V_{10}$, and $\mathrm{V}_{13}$ are also related to the development of RP $[13,14]$. Mean Lung Dose (MLD), or the average dose in proportion to total lung volume, has been reported as the best predictor of RP grade $>3$ (OR, 1.002; 95\% IC, $1.000-1.003 ; p=0.03)$ [15].

3. Fractionation: For SBRT, the total dose of radiation treatment (40-70 Gy) is divided into large doses by fractions, thus shortening exposure time (1-2 weeks). When larger doses per fraction used (e.g., 50 Gy in 5 fractions), $\mathrm{V}_{20}>10 \%$, and a mean lung dose $>6$ Gy are associated with a higher risk of RP grade $\geq 2$ [16]. A recent multicenter trial compared the impact of the fractionation scheme-daily vs. every other day-on toxicities. There, the patients treated daily experienced significantly higher grade $>2$ toxicities than the every-other-day patients (43 vs. $7 \%, p<0.001$ ) [17].

4. Chemotherapy: Chemotherapeutic agents like doxorubicin, taxanes, bleomycin, cyclophosphamide, vincristine, mitomycin, gemcitabine, and bevacizumab recognized as radiotherapy sensitizers due to their synergistic effect [18-20]. Taxane-induced pneumonitis seems to be higher when these agents combined with other cytotoxic drugs, especially gemcitabine.

5. Concurrent treatment with chemo-radiotherapy (CCRT): Patients who receive combinations with cytotoxic agents have a higher frequency of lung toxicity compared with those who receive monotherapy (32 vs. 6\%) $[5,21]$. Remarkable, in an international cohort, radiation pneumonitis was increased in patients $>65$ years treated with a platinum-taxanes combination [21]. However, a 2012 meta-analysis with over 1,600 patients demonstrated an increased OR of $1.6(1.11-2.32)$ for RP in patients receiving concurrent treatment compared to sequential chemotherapy [22]. Furthermore, induction chemotherapy before concomitant treatment could increase the risk of RP, probably due to the prior radiosensitizing contribution of chemotherapy [23].

6. $Y^{90}$ microsphere radioembolization: Radioembolization delivers directed intraarterial doses of yttrium-90 $\left(\mathrm{Y}^{90}\right)$ for treating hepatocellular carcinoma and liver metastases. RP is one of the most critical risks of radioembolization. Significant shunting to the lungs may result in lung toxicity, which has related to lung shunt fraction of more than 13\% [24, 25]. During the planning of $\mathrm{Y}^{90}$ radioembolization, the assessment of splanchnic and pulmonary shunting may predict lung deposition of microspheres, and the risk for RP [26].

7. Immunotherapy: Pneumonitis due to immunotherapy is a rare but potentially life-threatening immune-related Adverse Event (irAE) derived from a direct cytotoxic effect, oxidative stress, and immunemediated injury. The time elapsed between immunotherapy and the presence of pneumonitis varies

Table 1 Grading system for radiation induced lung toxicity

\begin{tabular}{|c|c|c|c|}
\hline & RTOG & CTCAE v. 5.0 & SWOG \\
\hline Grade 0 & No changes & No changes & Normal \\
\hline Grade 1 & Asymptomatic or mild symptoms & $\begin{array}{l}\text { Asymptomatic, only radiological, or tomographic } \\
\text { findings }\end{array}$ & $\begin{array}{l}\text { Radiographic changes, symptoms } \\
\text { do not require steroids }\end{array}$ \\
\hline Grade 2 & $\begin{array}{l}\text { Moderate symptoms of pneumonitis (severe } \\
\text { cough) and radiographic changes (radiographic } \\
\text { patches) }\end{array}$ & $\begin{array}{l}\text { Symptomatic, does not interfere with daily activi- } \\
\text { ties }\end{array}$ & Steroids required or tap of effusion \\
\hline Grade 3 & $\begin{array}{l}\text { Severe symptoms of pneumonitis, dense radio- } \\
\text { graphic changes }\end{array}$ & $\begin{array}{l}\text { Symptomatic, interferes with daily activities, } \\
\text { requires supplemental } \mathrm{O} 2\end{array}$ & Oxygen required \\
\hline Grade 4 & $\begin{array}{l}\text { Symptoms of severe respiratory failure requiring } \\
\text { assisted ventilation or continuous } \mathrm{O} 2\end{array}$ & $\begin{array}{l}\text { Threatens life, requires mechanical ventilation } \\
\text { support }\end{array}$ & Requires assisted ventilation \\
\hline Grade 5 & Death-related late effects of radiotherapy & Death related severe pneumonitis & - \\
\hline
\end{tabular}


from 1 to 24 months $[27,28]$. Combined treatment with anti-PD1/PD-L1 increases pneumonitis risk by 1.5-2 times, moreover, anti-PD-1/PD-L1 combined with anti-CTLA-4 risk is $10 \%$ compared to the use of monotherapy (3\%) [29, 30]. Furthermore, combination strategies of nivolumab and tyrosine-kinase inhibitors concomitantly or sequentially increase the risk of pneumonitis considerably [31]. Pneumonitis recurrence after rechallenge occurs in $60 \%$ of patients, and some cases even more extensively and severely [32-34]. Safety in re-treatment with immune checkpoint inhibitors does not depend entirely on the severity of the initial adverse event.

\section{Tumor-related factors}

1. Tumor location: Disease location in the mid-lower lung is more strongly associated with the development of RP [22, 35, 36]. Two possible explanations are 1) tumor motion may require a large lung radiated volume [37] and 2) patients can have inhomogeneous perfusion before RT due to previous lung diseases, tissue infiltrates, and cancer involvement. Thus, radiation may cause damage, which decreases perfusion and increases tissue density.

2. Tumor histology and staging: No association has yet been reported between tumor histology and RP development, while the effect of tumor stage in predicting RP risk is controversial.

3. Tumor volume: Patients with a higher tumor volume usually have a more significant lung and surrounding radiated volume. The most crucial factor that influences the development of RP is thus related to the percentage of lung radiated volume [13, 38].

\section{Patient-related factors}

1. Smoking: Smoking is deleterious for survival, noteworthy the effect on the increased risk of developing RILI is not clear. There is evidence that smoking could play a protective role in patients who underwent radiotherapy [39]. In the other hand, 20\% higher risk of developing pneumonitis has reported in smokers and current smokers [40]; contrary to the protective effect observed by Vogelius et al. (OR 0.7, $p<0.06)$ [22], and the higher incidence of RP in nonsmokers compared to former smokers (37 vs. 14\%) $[35,39]$. The protective effect of tobacco reinforced by the fact that smoking-damaged lungs have less radiosensitivity to injury due to non-functional air- spaces and non-vital tissue presence. However, this information should not encourage tobacco consumption in cancer patients.

2. Comorbid conditions: The most common pre-existing conditions in lung cancer patients are chronic obstructive pulmonary disease (COPD) and interstitial lung disease (ILD). COPD is found in $40-70 \%$ of patients and is an independent mortality prognostic factor in lung cancer patients; furthermore, an increase of RP has described. [41, 42] Patients with ILD often develop lung cancer within five years (15.4\%) [41]. ILD has related to a considerably increased risk of any grade and fatal RP in patients with pre-radiotherapy computerized tomography (CT) scan findings [43]. Moreover, no differences in any grade of RP or mortality associated with ILD in subclinical patients who underwent SBRT [44]. COPD and ILD patients with RILI might be more symptomatic due to their impaired lung function, which leaves them highly susceptible to small changes [38, 45]. It also seems that in a lower grade, pulmonary emphysema has related to the development of RP in non-small cell lung cancer (NSCLC) patients [46, 47].

3. Age and sex: Women have a lower lung volume than men, yet in most studies, the association with RP risk has not been demonstrated [35]. Older patients may be more likely than younger ones to have a lower general functional status, comorbidities, and reduced lung function, which may explain the high RP risk [46]. Although the cut-off point for defining young versus old patients could bias the estimated effect, elderly patients $>70$ reported to have worse RP (6\% vs. $1 \%$ ), often associated with RP grade $\geq 2$ [39]. Therefore, RP risk should be considered in patients of all ages, but other factors must also be considered.

4. Genetic phenotypes: Genetic variation in crucial genes in DNA replication and repair, inflammation, and oxidative stress pathways, may either ameliorate or exacerbate the effects of a given radiation dose on the lungs. The risk of RP increases as the number of unfavorable genotypes increases (see Table 2).

\section{Pathophysiology of radiation-induced pneumonitis}

Radiation induces a loss of the alveolar barrier function by destroying epithelial and endothelial cells. The inflammatory response induces a cycle of increased inflammation, vascular permeability, and cytokine release within days or weeks [32, 48]. Macrophage accumulation and activation contribute to the development of hypoxia, stimulating the production of reactive oxygen species and reactive nitrogen species (ROS/RNS) 
Table 2 Genes associated with lung radiation toxicity

\begin{tabular}{|c|c|c|c|c|}
\hline Study & & Gene associated with lung toxicity year & Gene function & References \\
\hline \multirow[t]{3}{*}{ Pu et al. } & 2014 & $\begin{array}{l}\text { RPCDC2 (rs10711) and (rs1871445) DDX58 } \\
(\text { rs1 1795343) and (rs7865082) FGF5 (rs3733336) }\end{array}$ & Inflammation & {$[87]$} \\
\hline & & ETS2 (rs2298560) LIMS1 (rs12469016) & & \\
\hline & & GHR (rs4292454) TFEB (rs13202921) & & \\
\hline \multirow[t]{2}{*}{ Wen et al. } & 2014 & RP LIN28B (rs314280) & RNA binding protein & {$[88]$} \\
\hline & & LIN28B (rs314276) & & \\
\hline Pang et al. & 2013 & HSPB1 (rs2868371) & Oxidative stress pathways & {$[89]$} \\
\hline Xiong et al. & 2013 & ATM (rs189037) and (rs228590) & DNA repair & {$[90]$} \\
\hline Kelsey et al. & 2013 & XRCC1 (rs25487) DNA repair BRCA1 (rs16942) & DNA repair & [91] \\
\hline Mak et al. & 2012 & MTHFR (rs1801131) & Oxidative stress pathways & [92] \\
\hline Xu et al. & 2015 & LIG4 (rs1805388) & DNA repair & [93] \\
\hline Yin et al. & 2012 & VEGF (rs2010963) and (rs3025039) & Angiogenesis & [94] \\
\hline Niu et al. & 2012 & TGF- $\beta 1$ (rs11466345) & Inflammation & {$[95]$} \\
\hline Wang et al. & 2008 & P53 Arg72Pro & $\begin{array}{l}\text { Cell-cycle regulation, apoptosis, } \\
\text { and DNA repair }\end{array}$ & {$[96]$} \\
\hline \multirow[t]{5}{*}{ Hildebrandt et al. } & 2010 & RPIL1A (rs1800587/rs17561) IL-8 (rs4073) & Inflammation & {$[97]$} \\
\hline & & TNF (rs1799724) TNFRSF1B (rs1061622) & & \\
\hline & & MIF (rs7555622) IL4 (rs2243250) IL4R & & \\
\hline & & (rs2070874) IL13 (rs10800925) IL13 (rs20541) & & \\
\hline & & NFKBIA (rs1799983) NOS3 (rs1799983) & & \\
\hline Zhang et al. & 2010 & ATM (rs189037) and (rs373759) & DNA repair & {$[98]$} \\
\hline Yuan et al. & 2009 & TGF- $\beta 1$ (rs1982073) & Inflammation & [99] \\
\hline
\end{tabular}

Transforming growth factor-beta 1 (TGF- $\beta 1$ ), Deoxyribonucleic-acid (DNA), Ribonucleic-acid (RNA)

and proinflammatory, profibrogenic and proangiogenic cytokines that perpetuate a non-healing tissue response that leads to chronic radiation injury [49]. The changes induced by radiation can be divided into five phases according to exposure time (see Fig. 1).

1. Early phase begins within hours or days of RT and consists of vascular congestion that induces leukocyte infiltration, pneumocytes type I apoptosis, and intra-alveolar edema. The first cytokines released within two weeks post-radiotherapy and include the following: tumor necrosis factor- $\alpha$ (TNF- $\alpha$ ), interleukin-1 (IL-1), interleukin-6 (IL-6), high-molecular-weight mucin-like antigen KL-6, platelet-derived growth factor- $\beta$ (PDGF- $\beta$ ), and basic fibroblastic growth factor (bFGF) [50]. A second wave activates 6-8 weeks post-radiation and is associated with increased oxidative damage to the DNA, hypoxia, decreased lung perfusion, and increased expression of transforming growth factor-beta 1 (TGF- $\beta 1$ ) [51].

2. Latent phase characterized by augmented secretions due to the proliferation of respiratory goblet cells and ciliary cell malfunction. It accompanied by trachealbronchial hypersecretion and degenerative changes in the alveolar epithelium and endothelium [52].
3. Exudative phase is also known as the clinical RP phase and occurs 3-12 weeks after RT exposure. It consists of epithelial and endothelial detachment that causes alveolar collapse accompanied by a narrowing of the pulmonary capillaries and microvascular thrombosis. The desquamation of pneumocytes and the alveolar secretion of a fibrin-rich exudate contribute to the formation of hyaline membranes. Also, the alveolar restitution characterized by the proliferation of pneumocyte type II re-epithelializing the alveolar basement membrane [53].

4. Intermediate phase refers to the dissolution of hyaline membranes, which occurs following the synthesis of collagen by fibroblasts that migrate and proliferate in the alveolar walls. The importance of TGF- $\beta 1$ expression is based on the influx of fibroblasts and their conversion to myofibroblasts, which produces lung fibrosis. This condition, in turn, leads to hypoxia, which induces the release of both profibrogenic and proangiogenic factors, so this cycle continues until it reaches the ultimate stage of chronic lung disease [52].

5. Fibrotic phase can appear after six months of radiation exposure. It evolved biologically for several years and characterized by hyperplastic pneumocytes, increased myofibroblasts, and extensive col- 


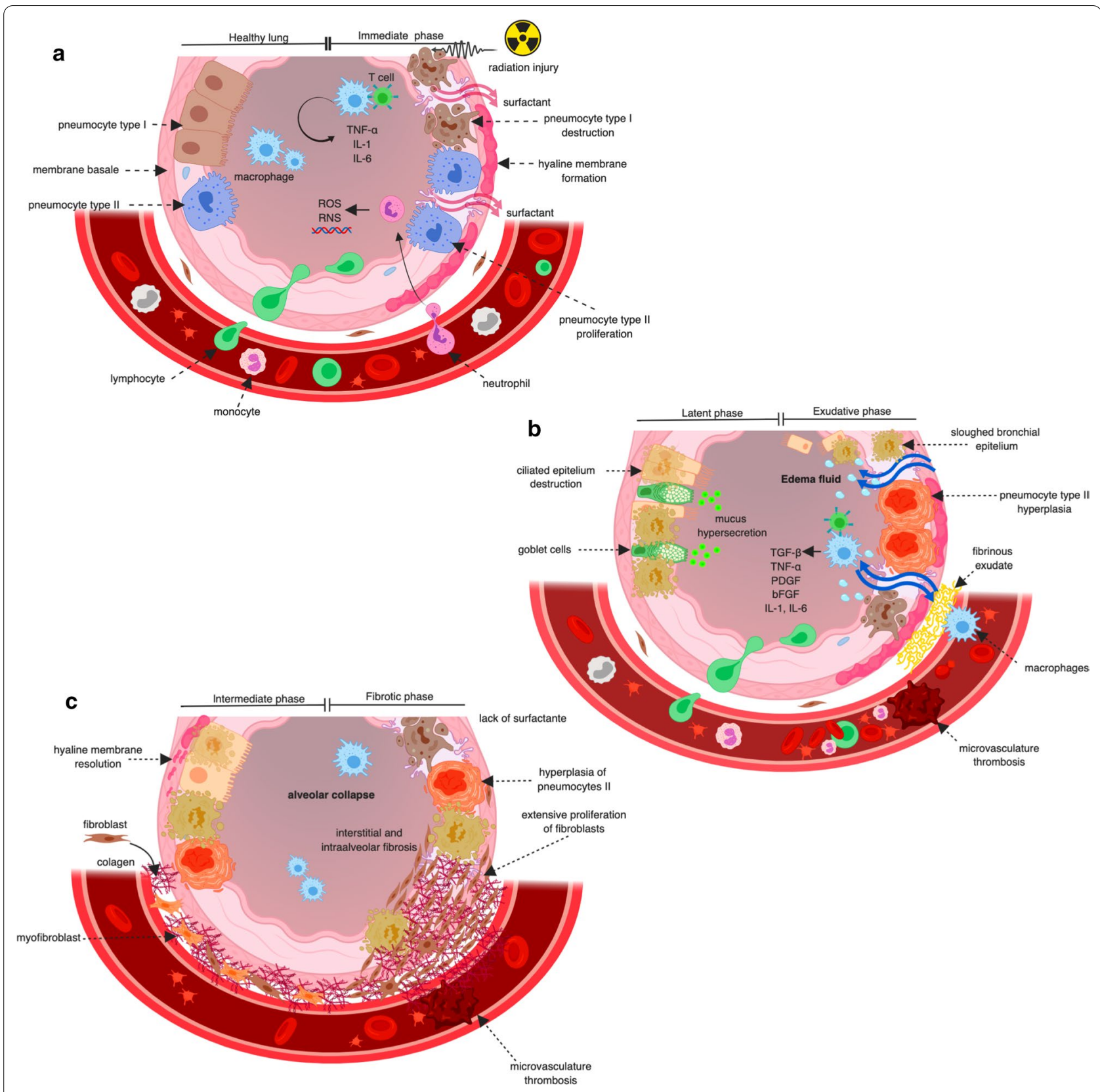

Fig. 1 Pathophysiology and signaling pathways involved in pulmonary irradiation. a Healthy lung and radiation lung injury: early phase; b Radiation lung injury: latent and exudative phases; c Radiation lung injury: intermediate and fibrotic phases. TNF-a: tumor necrosis factor-a; IL-1: interleukin-1; IL-6: interleukin-6; PDGF- $\beta$ : platelet-derived growth factor- $\beta$;bFGF: basic fibroblastic growth factor; ROS: release of reactive oxygen species; RNS: reactive nitrogen species; TGF- $\beta 1$ : transforming growth factor-beta. Created in Biorender. https://biorender.com/

lagen depositions in the pulmonary interstitium and alveoli. These deposits lead to the collapse of alveolar spaces, thus reducing pulmonary volume [54].

\section{Radiation recall pneumonitis}

Radiation recall pneumonitis (RRP) is an acute inflammatory response in a previously irradiated lung after the administration of systemic antineoplastic agents [55]. It often begins after exposure to the triggering agent but may occur at any time during treatment. The time elapsed from treatment onset to the presence of 
RRP ranges from hours to years, and the severity does not correlate with the interval of time between radiotherapy and antineoplastic treatment [56]. Taxanes and anthracyclines are the most common drugs related to RRP. Like nivolumab or durvalumab, immune-checkpoint inhibitors have reported higher incidences of severe pneumonitis in the irradiated lungs of previously treated NSCLC patients $[34,57]$. Chemotherapy agents may be more likely than immunotherapy to be related to RRP; thus, the rate and severity of this phenomenon will change as the use of immunotherapy and targeted therapies become the preferable upfront treatment in the majority of clinical scenarios.

\section{Clinical approach}

Clinical diagnosis often complicated due to the presence of non-specific symptoms that may be related to either pre-existing pathologies or malignant diseases. Thoracic radiation produces acute and late clinical manifestations after lung injury. RILI can divide into an acute phase ( $<6$ months), also called RP, and a chronic phase ( $>6$ months) known as RF [58-60]. Some authors refer to the acute phase as the development of pneumonitis that lasts from 4 to 12 weeks after radiation [61]. In acute lung injury, patients may experience an exacerbation of previous respiratory symptoms or new clinical manifestations, such as dyspnea and coughing, which occur in $20-40 \%$ of cases [62]. Severe signs and symptoms are less frequent but involve hypoxemia and respiratory failure. Conversely, the chronic phase manifests itself as progressive respiratory insufficiency or progressed severity of previous symptoms, particularly dyspnea. Non-specific signs and symptoms include tachypnea, cyanosis, crackles or pleural rub under thorax examination, chest pain, malaise, and occasionally, fever. Moreover, less frequent RP clinical features may include hemoptysis, airway obstruction, pulmonary vascular damage, bronchitis, respiratory infections, pleural effusion, and pneumothorax. The physical examination finding may include pleural friction rub, moist rales, and signs of consolidation.

\section{Grading}

There are different grading systems defined pneumonitis severity, regarding clinical, radiological changes, and type of treatment or medical support required. The most commonly used are the Radiation Therapy Oncology Group (RTOG) [63], the Common Terminology Criteria for Adverse Events v. 5.0 (CTCAE v 5.0) [64], and the Southwest Oncology Group Criteria (SWOG) [65]. RP events scored by the RTOG and CTCAE v 5.0 standards classify symptoms and image findings into five grades, while the SWOG score focuses on treatment requirements (see Table 1).

\section{Image abnormalities}

There is a broad spectrum of imaging findings after radiation injury that can mimic other etiologies. The extension of RP damage varies according to the radiological image observed. It can display from scarce patchy lesions within the irradiated field with fading of the pulmonary vasculature to very extensive lesions with well-defined areas of consolidation. A chest X-ray is the first tool used in approaches to RP. Radiographic lung damage sees in lung volumes irradiated at doses under 20 Gy. Newer techniques like VMAT or IMRT have the potential to deliver lower doses of radiation distributed in lung volumes. V5, V10, and V15 dose constraints are correlated with RP, however, V5 has linked with symptomatic RP [66]. VMAT and IMRT should be employed as the prefer radiation techniques in addition to strict dosimetric constraints. CT-scan is more sensitive than chest radiography for detecting subtle lung injury following radiation treatment. Different CT findings have described in RP: diffuse ground-glass opacity, modified conventional, mass-like consolidation with volume loss and traction bronchiectasis, and scar-like $[48,67,68]$.

Conventional RF generally involves the entirety of irradiated lung tissue. Acute image findings are usually confined to the radiation field and appear as ground-glass opacities that may progress to the organizing or consolidation phases $[61,68]$. Also, it can be present as ipsilateral pleural effusion and atelectasis. Lung opacities may gradually resolve over six months without radiological sequelae or with minimal damage [51]. Late radiological findings result from unresolved acute RP. They include diminished volume, linear scarring, consolidation, and traction bronchiectasis.

In some cases, pleural thickening and mediastinum traction may be observed [48]. In advanced stages, shrinkage of the pulmonary parenchyma and areas of fibrosis along the path of the radiation beam may be visible. RF and loss of lung volume may continue to evolve for as long as 24 months, resulting in architectural distortion [53] (see Fig. 2). Kouloulias et al. proposed a CT grading scale to categorize lung damage's extension and characteristics in 5 scores, but further studies are required to validate its use [50].

\section{Pulmonary function tests}

Reduced baseline mechanical function measured by spirometry, plethysmography, and gas exchange 

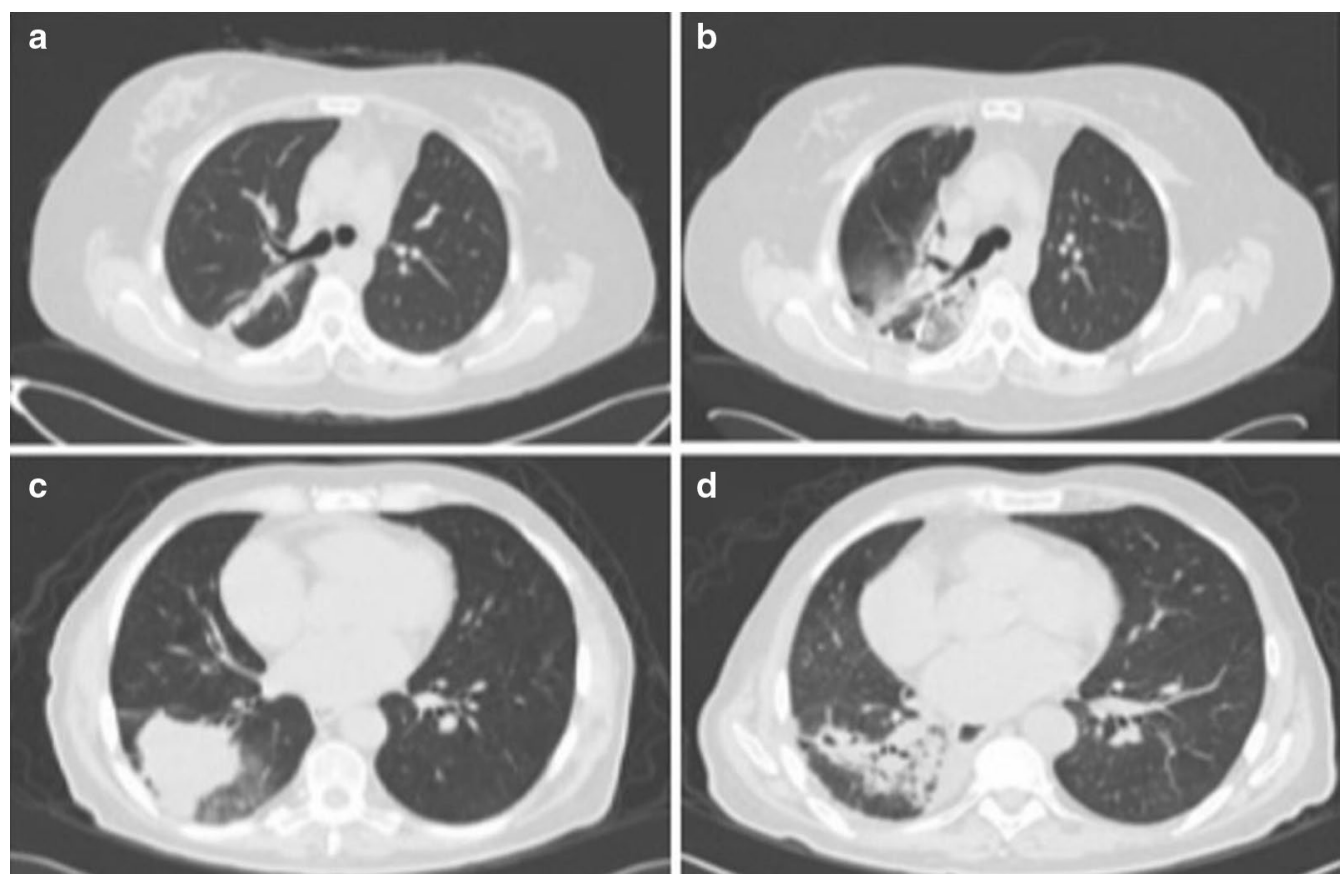

Fig. 2 Imaging findings after radiation injury that can mimic other etiologies. a Axial images of a CT scan performed 1-week before RT and three months post-RT; $\mathbf{b}$ A ground-glass opacity image with atelectasis; $\mathbf{c}$ Axial images of a CT scan with tumor image in the lower lobe before RT and six months post-RT; $\mathbf{d}$ Consolidation, bronchiectasis, and a scar-like pattern.

abnormalities on the diffusion lung capacity of carbon monoxide test (DLCO) has elucidated as predictive factors for RP $[16,54]$. The lung is not a uniform organ, and patients with lung cancer experience distinct changes in response to RT in different functional regions [37]. After RT, a mild decrease in the forced expiratory volume in $1 \mathrm{~s}\left(\mathrm{FEV}_{1}\right)$ may indicate minor development of bronchial obstruction due to tissue swelling. Declines in forced vital capacity (FVC) and total lung capacity (TLC) indicate a degree of lung stiffening since both are indicators of lung compliance. As larger volumes are irradiated, a more significant decrease in lung compliance seems to appear, affecting FVC, TLC, and, subsequently, $\mathrm{FEV}_{1}$. A reduction of DLCO after RT refers to an interstitial lung tissue damage that compromises the gas transfer through the alveolocapillary membrane. The six-minute walking test (6-MWT) is a useful predictor tool for RP in patients undergoing thoracic irradiation for lung carcinoma. A 6-MWT/FVC ratio below $4 \mathrm{ft} / 1$ predicts chronic RP [69]. A prospective study in NSCLC patients evaluating lung function with a broad range of lung function tests showed that a reduction in baseline $\operatorname{FEV}_{1}(p=0.02)$ and DLCO $(p=0.02)$, together with an increase in the fractional exhaled nitric oxide (FeNO) test $(p=0.04)$, correlate with the development of RP [70]. Likewise, a reduction in lung function observed before symptoms appear in patients with radiation-induced lung injury. Pulmonary function tests have proven to be useful tools for the early detection of lung tissue changes secondary to radiation $[71,72]$.

\section{Diagnosis and treatment}

Diagnoses of RP require clinical correlation and exclusion of the most common pathologies that mimic lung toxicity, mainly disease progression and infection. It is essential to differentiate these conditions to provide adequate treatment and proper management. RP is a diagnosis established by clinical suspicion or radiological findings; in selected cases, a lung biopsy helped to rule out confounders.

The mainstay of treatment in acute pneumonitis consists of administering a systemic corticosteroid cycle at high doses for symptomatic patients or those with subacute onset, grade $\geq 2$; however, few controlled studies have evaluated the efficacy of RP treatment in humans. Oral prednisone generally prescribed at $1-2 \mathrm{mg} / \mathrm{kg} / \mathrm{day}$ before tapering down over 3-12 weeks, depending on institutional recommendations, is an option [73]. For grades 3-4, intravenous corticosteroids equivalent to methylprednisolone at $2-4 \mathrm{mg} / \mathrm{kg} / \mathrm{day}$ tapered over six 


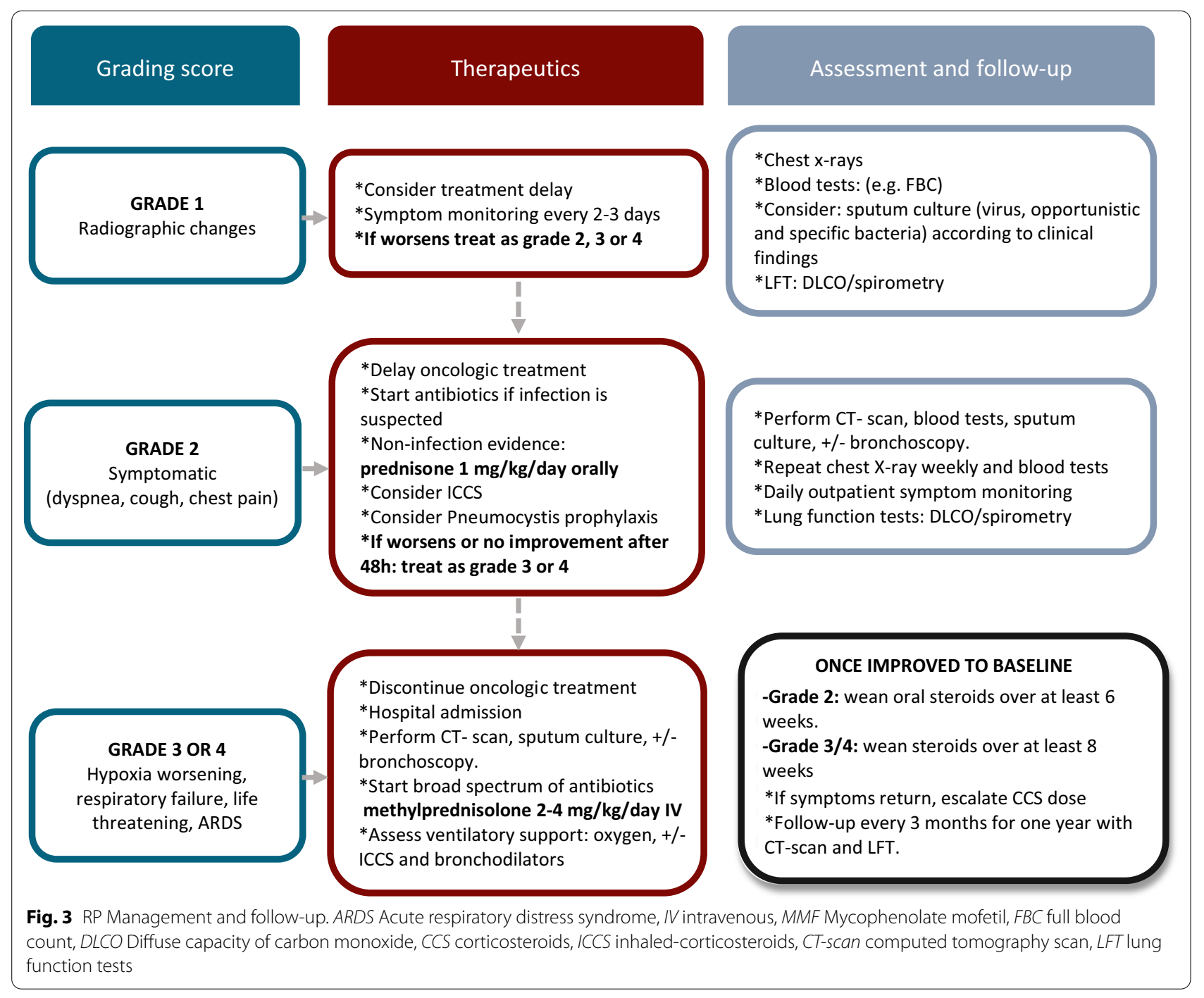

weeks is recommended. Glucocorticoids reduce inflammation and inhibit TNF-induced nitric oxide-mediated endothelial cell and lymphocyte toxicity. Prophylaxis for Pneumocystis Jirovecci recommended for patients with risk factors and those taking high dose corticosteroids (see Fig. 3) [74, 75]. The use of inhaled corticosteroids ensures that the highest dose is deposited in the airway, thus decreasing side effects. Although there is no fixed treatment dosage, inhaled steroids have shown efficacy as a treatment option for RP grade 2 [76]. However, few studies have assessed the efficacy of inhaled steroids in cancer patients. It is well-known that patients with chronic disease (radiation fibrosis) are unlikely to benefit from glucocorticoid therapy [60].

\section{Prophylaxis and new treatment options}

Several strategies have tested prophylactically or in the early stages of RP to avoid fibrosis development; however, despite positive results, none of the following are standard of care in the current clinical practice. Pentoxifylline has immunomodulatory and anti-inflammatory properties mediated by the suppression of TNF- $\alpha$ and IL-1, which may play a role in treating of RF. The effects of pentoxifylline at a dose of $400 \mathrm{mg}$, taken orally three times a day for eight weeks, have proven to improve clinical signs, symptoms, and a reduction in lung fibrosis [77]. It significantly reduces the presence of fibrosis with alpha tocopherol (vitamin E) for six months [78-80].

Amifostine is a radioprotector agent that functions via free radical scavenging. In animal models, it diminishes the concentration of TGF- $\beta 1$ [81]. Two meta-analyses evaluated and verified the benefit of amifostine at reducing the risk of RP vs. placebo/non-treatment, without affecting tumor response [82, 83].

Angiotensin-converting enzyme inhibitors (ACEinhibitors) exhibit significant antifibrotic activity against 
collagen accumulation in the lungs; however, its effectiveness has proved in retrospective trials [84, 85]. Since excess collagen synthesis is a crucial histopathologic feature of RF, other drugs, such as colchicine, penicillamine, statins, and interferon-gamma, may also have the potential to modify the progression of fibrosis.

Recently, nintedanib has emerged as a promising form of treatment and prophylaxis for RF (NTC 02452463, NTC02496585), since it showed benefits reducing the annual FVC decline in patients with idiopathic pulmonary fibrosis that shares similar pathophysiology [86].

\section{Conclusions}

Pneumonitis is a potentially life-threatening adverse event caused by treatment that has become more common since the introduction of new, personalized therapies. Some progress has made in elucidating its multifactorial mechanism, and various risk factors have identified to implement preventive strategies. However, there are still enormous gaps in our knowledge, particularly about the role of specific cytokines as predictive factors, the use of accurate diagnostic tests, and the advent of new prophylactic and curative therapeutic solutions. Achieving a better understanding of the pathophysiology of pneumonitis is still the focus of efforts to develop new treatments and prophylactic drugs. These facts highlight the essential role of patient follow-up when receiving RT. The principal focus of future research should be developing individualized clinical and lung function monitoring, specific therapies, preventing, and reducing sequelae.

\footnotetext{
Abbreviations

RILI: Radiotherapy induced lung injury; RP: Radiation pneumonitis; RF: Radiation fibrosis; RT: Radiotherapy; SBRT: Stereotactic body radiation therapy; IMRT: Intensity-modulated radiotherapy; VMAT: Volumetric arc radiotherapy; MLD: Mean lung dose; CCRT: Chemo-radiotherapy; $Y^{90}$ : Yttrium-90; irAE: Immunerelated adverse event; COPD: Chronic obstructive pulmonary disease; ILD: Interstitial lung disease; CT: Computerized tomography; NSCLC: Non-small cell lung cancer; ROS: Reactive oxygen species; RNS: Reactive nitrogen species; TNF-a: Tumor necrosis factor-a; IL-1: Interleukin-1; IL-6: Interleukin-6; PDGF- $\beta$ : Platelet-derived growth factor- $\beta$; bFGF: Basic fibroblastic growth factor; TGF$\beta 1$ :Transforming growth factor-beta 1; RRP: Radiation recall pneumonitis; RTOG: Radiation Therapy Oncology Group; CTCAE v 5.0: Common terminology criteria for adverse events v.5.0; SWOG: Southwest oncology group criteria;

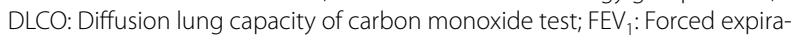
tory volume in 1s; FVC: Forced vital capacity; TLC: Total lung capacity; 6-MWT: Six-minute walking test; FeNO: Fractional exhaled nitric oxide; ACE-inhibitors: Angiotensin-converting enzyme inhibitors; ARDS: Acute respiratory distress syndrome; IV: Intravenous; MMF: Mycophenolate mofetil; FBC: Full blood count; DLCO: Diffuse capacity of carbon monoxide; CCS: Corticosteroids; ICCS: Inhaled-corticosteroids; LFT: Lung function tests.
}

Acknowledgements

Not applicable.

\section{Authors' contributions}

Dr. OA and Dr. MAH designed the work, participated substantially in data acquisition and interpretation. Dr. FM, Dr. WMM, and Dr. MNB participated in the review and writing of the manuscript content. Dr. FLR revised the manuscript critically for relevant intellectual content. All authors contributed to data analysis, drafting, and revising the paper. They approved the final version of the manuscript and agreed to be accountable for all the work. All authors read and approved the final manuscript.

\section{Funding}

This research did not receive any specific grant from funding agencies in the public, commercial, or not-for-profit sectors.

\section{Availability of data and materials \\ Not applicable.}

\section{Ethics approval and consent to participate} Not applicable.

\section{Consent for publication}

Not applicable. The CT-scan images presented are illustrative; thus, they do not compromise anonymity and do not need patient consent.

\section{Competing interests}

Oscar Arrieta has received honoraria as an advisor, participated in speakers' bureau and given expert opinions to Pfizer, AstraZeneca, BoehringerIngelheim, Roche, Lilly, and Bristol-Myers Squibb. The other authors have no conflicts of interest to declare.

\section{Author details}

${ }^{1}$ Head of Thoracic Oncology Unit, Unidad Funcional de Oncología Torácica, Instituto Nacional de Cancerología (INCan), Av. San Fernando \#22, Sección XVI, Tlalpan, 14080 México City, CDMX, México. ${ }^{2}$ Departamento de Radioncología, Hospital Universitario HM Sanchinarro, Caracas, Venezuela.

Received: 29 October 2019 Accepted: 14 December 2020

Published online: 06 January 2021

\section{References}

1. Arrieta O, Guzmán-de Alba E, Alba-López LF, Acosta-Espinoza A, AlatorreAlexander J, Alexander-Meza JF, et al. [National consensus of diagnosis and treatment of non-small cell lung cancer]. Revista de investigacion clinica; organo del Hospital de Enfermedades de la Nutricion. 2013;65 Suppl 1:S5-84.

2. Luis AM. Radiotherapy for non-malignant diseases. Rep Pract Oncol Radiother. 2013;18:S14-5.

3. Bledsoe TJ, Nath SK, Decker RH. Radiation pneumonitis. Clin Chest Med. 2017;38(2):201-8.

4. Bradley JD, Hope A, El Naqa I, Apte A, Lindsay PE, Bosch W, et al. A nomogram to predict radiation pneumonitis, derived from a combined analysis of RTOG 9311 and institutional data. Int J Radiat Oncol Biol Phys. 2007;69(4):985-92.

5. Young Hee PJ-SK, Park YH, Kim JS. Predictors of radiation pneumonitis and pulmonary function changes after concurrent chemo-radiotherapy of non-small cell lung cancer. Radiat Oncol J. 2013;31:34-40.

6. Zhou Z, Song X, Wu A, Liu H, Wu H, Wu Q, et al. Pulmonary emphysema is a risk factor for radiation pneumonitis in NSCLC patients with squamous cell carcinoma after thoracic radiation therapy. Sci Rep. 2017;7(1):2748.

7. Fujimoto D, Kato R, Morimoto T, Shimizu R, Sato Y, Kogo M, et al. Characteristics and prognostic impact of pneumonitis during systemic anticancer therapy in patients with advanced non-small-cell lung cancer. PLOS ONE. 2016;11(12):e0168465.

8. Giuranno L, lent J, De Ruysscher D, Vooijs MA. Radiation-induced lung injury (RILI). Front Oncol. 2019;9:877.

9. van Sornsen de Koste J, Voet P, Dirkx M, van Meerbeeck J, Senan S, Rotterdam Oncological Thoracic Study G. An evaluation of two techniques for beam intensity modulation in patients irradiated for stage III non-small cell lung cancer. Lung Cancer. 2001;32(2):145-53.

10. Prezzano KM, Ma SJ, Hermann GM, Rivers Cl, Gomez-Suescun JA, Singh AK. Stereotactic body radiation therapy for non-small cell lung cancer: a review. World J Clin Oncol. 2019;10(1):14-27. 
11. Tsujino K, Hashimoto T, Shimada T, Yoden E, Fujii O, Ota Y, et al. Combined analysis of V20, VS5, pulmonary fibrosis score on baseline computed tomography, and patient age improves prediction of severe radiation pneumonitis after concurrent chemo-radiotherapy for locally advanced non-small-cell lung cancer. J Thorac Oncol. 2014;9(7):983-90.

12. Matsuo Y, Shibuya K, Nakamura M, Narabayashi M, Sakanaka K, Ueki N, et al. Dose-volume metrics associated with radiation pneumonitis after stereotactic body radiation therapy for lung cancer. Int J Radiat Oncol Biol Phys. 2012;83(4):e545-9.

13. Leprieur EG, Fernandez D, Chatellier G, Klotz S, Giraud P, Durdux C. Acute radiation pneumonitis after conformational radiotherapy for nonsmall cell lung cancer: clinical, dosimetric, and associated-treatment risk factors. J Cancer Res Ther. 2013;9(3):447-51.

14. Yorke ED, Jackson A, Rosenzweig KE, Braban L, Leibel SA, Ling CC. Correlation of dosimetric factors and radiation pneumonitis for non-small-cell lung cancer patients in a recently completed dose escalation study. Int J Radiat Oncol Biol Phys. 2005;63(3):672-82.

15. Harder EM, Park HS, Chen ZJ, Decker RH. Pulmonary dose-volume predictors of radiation pneumonitis following stereotactic body radiation therapy. Pract Radiat Oncol. 2016;6(6):e353-9.

16. Torre-Bouscoulet L, Munoz-Montano WR, Martinez-Briseno D, LozanoRuiz FJ, Fernandez-Plata R, Beck-Magana JA, et al. Abnormal pulmonary function tests predict the development of radiation-induced pneumonitis in advanced non-small cell lung Cancer. Respir Res. 2018;19(1):72.

17. Verma V, Shostrom VK, Zhen W, Zhang M, Braunstein SE, Holland J, et al. Influence of fractionation scheme and tumor location on toxicities after stereotactic body radiation therapy for large $(>/=5 \mathrm{~cm})$ non-small cell lung cancer: a multi-institutional analysis. Int J Radiat Oncol Biol Phys. 2017;97(4):778-85.

18. Lind JS, Senan S, Smit EF. Pulmonary toxicity after bevacizumab and concurrent thoracic radiotherapy observed in a phase I study for inoperable stage III non-small-cell lung cancer. J Clin Oncol. 2012;30(8):e104-8.

19. Wang CJ, Chang HT, Chang CY. Docetaxel-related interstitial pneumonitis. Ther Clin Risk Manag. 2015;11:1813-6.

20. Bielopolski D, Evron E, Moreh-Rahav O, Landes M, Stemmer SM, Salamon F. Paclitaxel-induced pneumonitis in patients with breast cancer: case series and review of the literature. J Chemother (Florence). 2017;29(2):113-7.

21. Palma DA, Senan S, Tsujino K, Barriger RB, Rengan R, Moreno M, et al. Predicting radiation pneumonitis after chemoradiation therapy for lung cancer: an international individual patient data meta-analysis. Int J Radiat Oncol Biol Phys. 2013;85(2):444-50.

22. Vogelius IR, Bentzen SM. A literature-based meta-analysis of clinical risk factors for development of radiation induced pneumonitis. Acta Oncol. 2012;51(8):975-83.

23. Mao J, Kocak Z, Zhou S, Garst J, Evans ES, Zhang J, et al. The impact of induction chemotherapy and the associated tumor response on subsequent radiation-related changes in lung function and tumor response. Int J Radiat Oncol Biol Phys. 2007;67(5):1360-9.

24. Salem R, Parikh P, Atassi B, Lewandowski RJ, Ryu RK, Sato KT, et al. Incidence of radiation pneumonitis after hepatic intra-arterial radiotherapy with yttrium-90 microspheres assuming uniform lung distribution. Am J Clin Oncol. 2008;31(5):431-8.

25. Peterson JL, Vallow LA, Johnson DW, Heckman MG, DiehI NN, Smith AA, et al. Complications after 90Y microsphere radioembolization for unresectable hepatic tumors: an evaluation of 112 patients. Brachytherapy. 2013;12(6):573-9.

26. Yu N, Srinivas SM, Difilippo FP, Shrikanthan S, Levitin A, McLennan G, et al. Lung dose calculation with SPECT/CT for (9)(0)Yittrium radioembolization of liver cancer. Int J Radiat Oncol Biol Phys. 2013;85(3):834-9.

27. Rashdan S, Minna JD, Gerber DE. Diagnosis and management of pulmonary toxicity associated with cancer immunotherapy. Lancet Respir Med. 2018;6(6):472-8.

28. Delaunay M, Cadranel J, Lusque A, Meyer N, Gounant V, Moro-Sibilot $D$, et al. Immune-checkpoint inhibitors associated with interstitial lung disease in cancer patients. Eur Respir J. 2017;50(2):1.

29. Naidoo J, Wang X, Woo KM, lyriboz T, Halpenny D, Cunningham J, et al. Pneumonitis in patients treated with anti-programmed death-1/programmed death ligand 1 therapy. J Clin Oncol. 2017;35(7):709-17.
30. Chuzi S, Tavora F, Cruz M, Costa R, Chae YK, Carneiro BA, et al. Clinical features, diagnostic challenges, and management strategies in checkpoint inhibitor-related pneumonitis. Cancer Manag Res. 2017;9:207-13.

31. Oshima Y, Tanimoto T, Yuji K, Tojo A. EGFR-TKI-associated interstitial pneumonitis in nivolumab-treated patients with non-small cell lung cancer. JAMA Oncol. 2018;4(8):1112-5.

32. Kainthola A, Haritwal T, Tiwari M, Gupta N, Parvez S, Tiwari M, et al. Immunological aspect of radiation-induced pneumonitis, current treatment strategies, and future prospects. Front Immunol. 2017;8:506.

33. Kumar V, Chaudhary N, Garg M, Floudas CS, Soni P, Chandra AB. Current diagnosis and management of immune related adverse events (irAEs) induced by immune checkpoint inhibitor therapy. Front Pharmacol. 2017:8:49.

34. Toi Y, Sugawara S, Kawashima Y, Aiba T, Kawana S, Saito R, et al. Association of immune-related adverse events with clinical benefit in patients with advanced non-small-cell lung cancer treated with nivolumab. Oncologist. 2018.

35. Kong F-MM, et al., Wang S. Nondosimetric risk factors for radiationinduced lung toxicity. Sem Radiat Oncol. 2015;25(2):100-9.

36. Zhang XJ, Sun JG, Sun J, Ming H, Wang XX, Wu L, et al. Prediction of radiation pneumonitis in lung cancer patients: a systematic review. J Cancer Res Clin Oncol. 2012;138(12):2103-16.

37. Yuan ST, Frey KA, Gross MD, Hayman JA, Arenberg D, Cai X-W, et al. Changes in global function and regional ventilation and perfusion on SPECT during the course of radiotherapy in patients with non-small-cell lung cancer. Int J Radiat Oncol*Biol*Phys. 2012;82(4):e631-e8.

38. Ren C, Ji T, Liu T, Dang J, Li G. The risk and predictors for severe radiation pneumonitis in lung cancer patients treated with thoracic reirradiation. Radiat Oncol. 2018;13(1):69.

39. Jin H, Tucker SL, Liu HH, Wei X, Yom SS, Wang S, et al. Dose-volume thresholds and smoking status for the risk of treatment-related pneumonitis in inoperable non-small cell lung cancer treated with definitive radiotherapy. Radiother Oncol. 2009;91(3):427-32.

40. Monson JM, Stark P, Reilly JJ, Sugarbaker DJ, Strauss GM, Swanson SJ, et al. Clinical radiation pneumonitis and radiographic changes after thoracic radiation therapy for lung carcinoma. Cancer. 1998;82(5):842-50.

41. Ozawa Y, Abe T, Omae M, Matsui T, Kato M, Hasegawa H, et al. Impact of preexisting interstitial lung disease on acute, extensive radiation pneumonitis: retrospective analysis of patients with lung cancer. PLOS ONE. 2015;10(10):e0140437.

42. Inoue T, Shiomi H, Oh RJ. Stereotactic body radiotherapy for Stage I lung cancer with chronic obstructive pulmonary disease: special reference to survival and radiation-induced pneumonitis. J Radiat Res. 2015;56(4):727-34.

43. Lee YH, Kim YS, Lee SN, Lee HC, Oh SJ, Kim SJ, et al. Interstitial lung change in pre-radiation therapy computed tomography is a risk factor for severe radiation pneumonitis. Cancer Res Treat. 2015;47(4):676-86.

44. Yamaguchi S, Ohguri T, Ide S, Aoki T, Imada H, Yahara K, et al. Stereotactic body radiotherapy for lung tumors in patients with subclinical interstitial lung disease: the potential risk of extensive radiation pneumonitis. Lung Cancer. 2013;82(2):260-5.

45. Sanuki N, Ono A, Komatsu E, Kamei N, Akamine S, Yamazaki T, et al. Association of computed tomography-detected pulmonary interstitial changes with severe radiation pneumonitis for patients treated with thoracic radiotherapy. J Radiat Res. 2012;53(1):110-6.

46. Kimura T, Togami T, Takashima H, Nishiyama Y, Ohkawa M, Nagata Y. Radiation pneumonitis in patients with lung and mediastinal tumours: a retrospective study of risk factors focused on pulmonary emphysema. $\mathrm{Br}$ J Radiol. 2012;85(1010):135-41.

47. Takeda A, Kunieda E, Ohashi T, Aoki Y, Oku Y, Enomoto T, et al. Severe COPD is correlated with mild radiation pneumonitis following stereotactic body radiotherapy. Chest. 2012;141(4):858-66.

48. Choi Yw Erasmus Jj MRF, et al., Choi YWEJJMRF. Effects of radiation therapy on the lung: radiologic appearances and differential diagnosis. Radiographics. 2004;24(4):985-97.

49. Tsoutsou PG, Koukourakis MI. Radiation pneumonitis and fibrosis: mechanisms underlying its pathogenesis and implications for future research. Int J Radiat Oncol Biol Phys. 2006;66(5):1281-93.

50. Kouloulias V, Zygogianni A, Efstathopoulos E, Victoria O, Christos A, Pantelis K, et al. Suggestion for a new grading scale for radiation induced pneumonitis based on radiological findings of computerized 
tomography: correlation with clinical and radiotherapeutic parameters in lung cancer patients. Asian Pac J Cancer Prev. 2013;14(5):2717-22.

51. Larici AR, del Ciello A, Maggi F, Santoro SI, Meduri B, Valentini V, et al. Lung abnormalities at multimodality imaging after radiation therapy for nonsmall cell lung cancer. Radiographics. 2011;31(3):771-89.

52. Small W Jr, Woloschak G. Radiation toxicity: a practical guide. Introduction. Cancer Treat Res. 2006;128:3-5.

53. Iyer R, Jhingran RlaA. Radiation injury: imaging findings in the chest, abdomen and pelvis after therapeutic radiation. Cancer Imaging. 2006;6(Special Issue A):S131-S9.

54. Justin M. Liam Laura Chow KLRSSPDM, Justin M. Liam Laura Chow Rodney Schmidt SPDMKL. The relationship between pulmonary function metrics and radiation-induced lung injury. Journal of Solid Tumors. 2013;3(1):6-13.

55. Levy A, Hollebecque A, Bourgier C, Loriot Y, Guigay J, Robert C, et al. Targeted therapy-induced radiation recall. Eur J Cancer. 2013;49(7):1662-8.

56. Ding X, Ji W, Li J, Zhang X, Wang L. Radiation recall pneumonitis induced by chemotherapy after thoracic radiotherapy for lung cancer. Radiat Oncol. 2011;6(1):24.

57. Antonia SJ, Villegas A, Daniel D, Vicente D, Murakami S, Hui R, et al. Durvalumab after chemoradiotherapy in stage III non-small-cell lung cancer. N Engl J Med. 2017;377(20):1919-29.

58. Giridhar P Rath Gk MS, et al., Giridhar PRGKMS. Radiation induced lung injury: Prediction, Assesment and Management. Asian Pacif J Cancer Prev. 2015;16:2613-7.

59. Simone CB 2nd. Thoracic radiation normal tissue injury. Semin Radiat Oncol. 2017:27(4):370-7.

60. Abratt Rp Silvestri G Morgan GWWP, Abratt Rp Silvestri GWPMGW. Pulmonary complications of radiation therapy. Clin Chest Med. 2004;25:167-77.

61. Ghaye B, Wanet M, El Hajjam M. Imaging after radiation therapy of thoracic tumors. Diagn Interv Imaging. 2016;97(10):1037-52.

62. Rodrigues $G$, Lock M, D'Souza D, Yu E, Van Dyk J. Prediction of radiation pneumonitis by dose-volume histogram parameters in lung cancer-a systematic review. Radiother Oncol. 2004;71(2):127-38.

63. Cox JD, Stetz J, Pajak TF. Toxicity criteria of the Radiation Therapy Oncology Group (RTOG) and the European organization for research and treatment of cancer (EORTC). International Journal of Radiation Oncology*Biology*Physics. 1995;31(5):1341-6.

64. SERVICES USDOHAH. Common Terminology Criteria for Adverse Events (CTCAE) 2017. Available from: https://ctep.cancer.gov/protocolDevelop ment/electronic_applications/docs/CTCAE_v5_Quick_Reference_5x7. pdf.

65. Green S, Weiss GR. Southwest Oncology Group standard response criteria, endpoint definitions and toxicity criteria. Invest New Drugs. 1992;10(4):239-53.

66. Jo IY, Kay CS, Kim JY, Son SH, Kang YN, Jung JY, et al. Significance of low-dose radiation distribution in development of radiation pneumonitis after helical-tomotherapy-based hypofractionated radiotherapy for pulmonary metastases. J Radiat Res. 2014;55(1):105-12.

67. Yamashita H, Takahashi W, Haga A, Nakagawa K. Radiation pneumonitis after stereotactic radiation therapy for lung cancer. World J Radiol. 2014;6(9):708-15.

68. Linda A, Trovo M, Bradley JD. Radiation injury of the lung after stereotactic body radiation therapy (SBRT) for lung cancer: a timeline and pattern of CT changes. Eur J Radiol. 2011;79(1):147-54.

69. Rawat S, Kumar G, Puri A, Sharma MK, Kakria A, Kumar P, et al. Correlation of six-minute walk test, pulmonary function test and radiation pneumonitis in the management of carcinoma of oesophagus: a prospective pilot study. J Radiother Pract. 2011;10(3):191-9.

70. Torre-Bouscoulet L, Arroyo-Hernandez M, Martinez-Briseno D, MunozMontano WR, Gochicoa-Rangel L, Bacon-Fonseca L, et al. Longitudinal evaluation of lung function in patients with advanced non-small cell lung cancer treated with concurrent chemoradiation therapy. Int J Radiat Oncol Biol Phys. 2018;101(4):910-8.

71. Wang J, Cao J, Yuan S, Ji W, Arenberg D, Dai J, et al. Poor baseline pulmonary function may not increase the risk of radiation-induced lung toxicity. Int J Radiat Oncol*Biol*Phys. 2013;85(3):798-804.

72. Claude L, Perol D, Ginestet C, Falchero L, Arpin D, Vincent M, et al. A prospective study on radiation pneumonitis following conformal radiation therapy in non-small-cell lung cancer: clinical and dosimetric factors analysis. Radiother Oncol. 2004;71(2):175-81.

73. Jain V, Berman AT. Radiation pneumonitis: old problem, new tricks. Cancers (Basel). 2018;10(7):1.

74. Baden LR, Swaminathan S, Angarone M, Blouin G, Camins BC, Casper $C$, et al. Prevention and Treatment of Cancer-Related Infections, Version 2.2016, NCCN Clinical Practice Guidelines in Oncology. J Natl Compr Canc Netw. 2016;14(7):882-913.

75. Liebling M, Rubio E, le S. Prophylaxis for Pneumocystis jiroveci pneumonia: is it a necessity in pulmonary patients on high-dose, chronic corticosteroid therapy without AIDS? Expert Rev Respir Med. 2015;9(2):171-81.

76. Henkenberens C, Janssen S, Lavae-Mokhtari M, Leni K, Meyer A, Christiansen $\mathrm{H}$, et al. Inhalative steroids as an individual treatment in symptomatic lung cancer patients with radiation pneumonitis grade II after radiotherapy? A single-centre experience. Radiat Oncol. 2016;11 (1):12.

77. Ozturk B, Egehan I, Atavci S, Kitapci M. Pentoxifylline in prevention of radiation-induced lung toxicity in patients with breast and lung cancer: a double-blind randomized trial. Int J Radiat Oncol*Biol*Phys. 2004;58(1):213-9.

78. Magnusson M, Höglund P, Johansson K, Jönsson C, Killander F, Malmström $P$, et al. Pentoxifylline and vitamin $E$ treatment for prevention of radiation-induced side-effects in women with breast cancer: a phase two, double-blind, placebo-controlled randomised clinical trial (Ptx-5). Eur J Cancer. 2009;45(14):2488-95.

79. Delanian S, Porcher R, Rudant J, Lefaix J-L. Kinetics of response to longterm treatment combining pentoxifylline and tocopherol in patients with superficial radiation-induced fibrosis. J Clin Oncol. 2005;23(34):8570-9.

80. Delanian S, Porcher R, Balla-Mekias S, Lefaix J-L. Randomized, placebo-controlled trial of combined pentoxifylline and tocophero for regression of superficial radiation-induced fibrosis. J Clin Oncol. 2003:21(13):2545-50.

81. Vujaskovic Z, Feng QF, Rabbani ZN, Samulski TV, Anscher MS, Brizel DM. Assessment of the protective effect of amifostine on radiation-induced pulmonary toxicity. Exp Lung Res. 2002;28(7):577-90.

82. Mell LK, Malik R, Komaki R, Movsas B, Swann RS, Langer C, et al. effect of amifostine on response rates in locally advanced non-small-cell lung cancer patients treated on randomized controlled trials: a meta-analysis. Int J Radiat Oncol Biol Phys. 2007;68(1):111-8.

83. Sasse AD, de Oliveira Clark LG, Sasse EC, Clark OAC. Amifostine reduces side effects and improves complete response rate during radiotherapy: results of a meta-analysis. Int J Radiat Oncol*Biol*Phys. 2006;64(3):784-91.

84. Ghosh SN, Zhang R, Fish BL, Semenenko VA, Li XA, Moulder JE, et al. Renin-angiotensin system suppression mitigates experimental radiation pneumonitis. Int J Radiat Oncol*Biol*Phys 2009;75(5):1528-36.

85. Kharofa J Tomic R CEP, et al., Kharofa JTRCEP. Decreased risk of radiation pneumonitis with incidental concurrent use of angiotensin-converting enzyme inhibitors and thoracic radiation therapy. Int J Radiat Oncol Biol Phys. 2012;84(1):238-43.

86. Richeldi L, du Bois RM, Raghu G, Azuma A, Brown KK, Costabel U, et al. Efficacy and safety of nintedanib in idiopathic pulmonary fibrosis. N Engl Med. 2014;370(22):2071-82

87. Pu X, Wang L, Chang JY, Hildebrandt MAT, Ye Y, Lu C, et al. Inflammationrelated genetic variants predict toxicity following definitive radiotherapy for lung cancer. Clin Pharmacol Ther. 2014;96(5):609-15.

88. Wen J, Liu H, Wang Q, Liu Z, Li Y, Xiong H, et al. Genetic variants of the LIN28B gene predict severe radiation pneumonitis in patients with non-small cell lung cancer treated with definitive radiation therapy. Eur J Cancer (Oxford, England: 1990). 2014;50(10):1706-16.

89. Pang $Q$, Wei $Q, X u T$, Yuan $X$, Lopez Guerra JL, Levy LB, et al. Functional promoter variant rs 2868371 of HSPB1 is associated with risk of radiation pneumonitis after chemoradiation for non-small cell lung cancer. Int J Radiat Oncol*Biol*Phys. 2013;85(5):1332-9.

90. Xiong H, Liao Z, Liu Z, Xu T, Wang Q, Liu H, et al. ATM polymorphisms predict severe radiation pneumonitis in patients with non-small cell lung cancer treated with definitive radiation therapy. Int J Radiat Oncol Biol Phys. 2013;85(4):1066-73.

91. Kelsey CR, Jackson IL, Langdon S, Owzar K, Hubbs J, Vujaskovic Z, et al. Analysis of single nucleotide polymorphisms and radiation sensitivity of the lung assessed with an objective radiologic endpoin. Clin Lung Cancer. 2013;14(3):267-74. 
92. Mak RH, Alexander BM, Asomaning K, Heist RS, Liu C-Y, Su L, et al. A single-nucleotide polymorphism in the methylene tetrahydrofolate reductase (MTHFR) gene is associated with risk of radiation pneumonitis in lung cancer patients treated with thoracic radiation therapy. Cancer. 2012;118(14):3654-65.

93. Xu F, Han J-C, Zhang Y-J, Zhang Y-J, Liu X-C, Qi G-B, et al. Associations of LIG4 and HSPB1 genetic polymorphisms with risk of radiation-induced lung injury in lung cancer patients treated with radiotherapy. Biomed Res Int. 2015;2015:1-6.

94. Yin M, Liao Z, Liu Z, Wang L-E, O'Reilly M, Gomez D, et al. Genetic variants of the nonhomologous end joining gene LIG4 and severe radiation pneumonitis in nonsmall cell lung cancer patients treated with definitive radiotherapy. Cancer. 2012;118(2):528-35.

95. Niu X, Li H, Chen Z, Liu Y, Kan M, Zhou D, et al. A study of ethnic differences in TGF $\beta 1$ gene polymorphisms and effects on the risk of radiation pneumonitis in non-small-cell lung cancer. J Thoracic Oncol. 2012;7(11):1668-75.

96. Wang S, Liao Z, Wei X, Liu HH, Tucker SL, Hu C, et al. Association between systemic chemotherapy before chemoradiation and increased risk of treatment-related pneumonitis in esophageal cancer patients treated with definitive chemoradiotherapy. J Thoracic Oncol. 2008;3(3):277-82.

97. Hildebrandt MAT, Komaki R, Liao Z, Gu J, Chang JY, Ye Y, et al. Genetic variants in inflammation-related genes are associated with radiation-induced toxicity following treatment for non-small cell lung cancer. PLOS ONE. 2010;5(8):e12402-e.

98. Zhang L, Yang M, Bi N, Fang M, Sun T, Ji W, et al. ATM polymorphisms are associated with risk of radiation-induced pneumonitis. Int J Radiat Oncol*Biol*Phys. 2010;77(5):1360-8.

99. Yuan X, Liao Z, Liu Z, Wang L-E, Tucker SL, Mao L, et al. Single nucleotide polymorphism at rs1982073:T869C of the TGF- $\beta 1$ gene is associated with the risk of radiation pneumonitis in patients with non-small-cell lung cancer treated with definitive radiotherapy. J Clin Oncol. 2009;27(20):3370-8.

\section{Publisher's Note}

Springer Nature remains neutral with regard to jurisdictional claims in published maps and institutional affiliations.
Ready to submit your research? Choose BMC and benefit from:

- fast, convenient online submission

- thorough peer review by experienced researchers in your field

- rapid publication on acceptance

- support for research data, including large and complex data types

- gold Open Access which fosters wider collaboration and increased citations

- maximum visibility for your research: over $100 \mathrm{M}$ website views per year

At BMC, research is always in progress.

Learn more biomedcentral.com/submissions 